\title{
Study on Early Warning Systems (EWS) for Indonesia Digital Terrestrial Television
}

\author{
Sulthon Faryabi Nurbadri ${ }^{1}$, Khoirul Anwar ${ }^{1}$, and Dharu Arseno ${ }^{2}$ \\ ${ }^{1}$ The Center for Advanced Intelligent Communications (AICOMS) \\ ${ }^{1,2}$ School of Electrical Engineering, Telkom University \\ *\{sulthonfaryabi@student.,anwarkhoirul@,darseno@\}telkomuniversity.ac.id
}

Manuscript received 15 Mei 2020; revised 18 June 2020; accepted 26 June 2020

\begin{abstract}
Early warning system (EWS) via digital television (TV) in Indonesia is still un-optimal in design and implementation due to the absent of clear standard/guidance to follow across the country. This paper studies various EWS based on digital TV of Japan, Korea, and the United States of America (USA). Although the systems look like different, the EWS can be simplified into 3 nodes representing (i) Emergency Agency, (ii) TV broadcaster, and (iii) TV receiver. Beside the 3-node-based EWS, this paper evaluates the possibilities of EWS having 4 nodes. We perform computer simulations to evaluate the latency and bit error rate (BER) performances under additive white Gaussian noise (AWGN) and frequency-flat Rayleigh fading channels. We found that the system latency and BER performances of EWS are highly affected by (i) the distance of one node to another and (ii) the number of nodes, where EWS with 3 or 4 nodes found to be enough and suitable for Indonesia digital TV. We propose a criterion of good EWS, i.e., total delay $T \leq t+4 \Delta t$ with $t$ and $\Delta t$ being the propagation delay and processing time, respectively, and BER less than $P_{b}=10^{-3}$. The result of this paper are expected to be used as a reference for the Indonesia EWS systems.
\end{abstract}

Keywords: Digital Television; Early Warning System; Broadcasting System; AWGN; Rayleigh Fading; Disaster Relief

DOI: $10.25124 /$ jmecs.v6i1.2827

\section{Introduction}

Information needs have led to demands for the transition of communication technology from analog to digital to improve performances. One of the phenomena of communication technology transition that can be seen is the television (TV). TV technology migration, analog to digital, has been planned since 2004, based on the technical and commercial perspective of the Telecommunications Union-Radiocommunication (ITU-R). The migration process from analog to digital is required because the performance of the digital system is more stable compared to the analogue system [1].

Indonesia is an archipelago that is very strategically located with a geographical position between the Indian and Pacific Oceans and a geological position, which is a meeting of three major world plates, the Indo-Australian Plate, the Eurasian Plate, and the $\mathrm{Pa}$ - cific plate. The meeting of three major world plates often causes disasters in Indonesia like earthquakes, tsunamis, and landslides that causing victims and damage. One of the ways to reduce the impacts is by applying an early warning system (EWS).

EWS is an emergency system for giving a warning as early as possible after a disaster occurs to reduce victims and damage. Some digital TV standards have implemented warning systems such as Integrated Services Digital Broadcasting (ISDB), Digital Multimedia Broadcasting (DMB) and, Advanced Television Systems Committee (ATSC), which are used by Japan, Korea, and America, respectively. Indonesian digital TV also has been implemented with a warning system corresponding to the ministry of communication and informatics regulations [2]. However, the emergency information regulation for Indonesia is not clear causing un-optimal implementation of digital TV in 


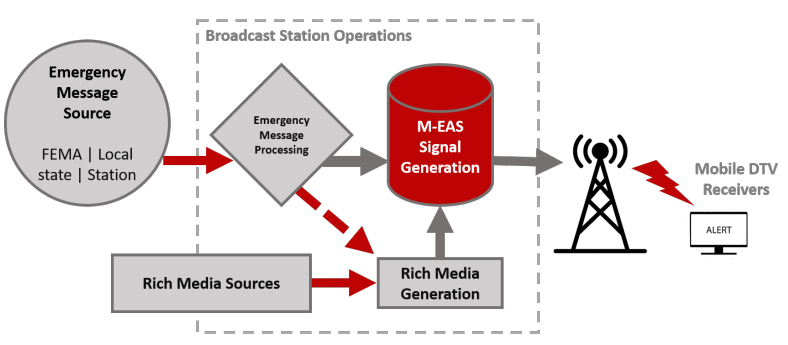

Fig. 1. M-EAS signal generation and transmission flow.

Indonesia.

Some research about emergency warnings via digital TV has already conducted, for example, DMB, a method for increasing emergency alert service efficiency in [3]. The technique proposed multiplexing to eliminate inter-channel interference. On integrated service digital broadcasting terrestrial (ISDB-T) standard, research for emergency warning has been conducted by [4]. The method in [4] can decrease the power consumption for the receivers during idle and decreasing false alarm detection for fixed users. Another research for an emergency warning on Digital Video Broadcasting Terrestrial (DVB-T) has been conducted by [5], where a system for detecting alert messages and converting the message into the transport stream for DVB-T is proposed. However, the EWS transmission scheme, in general, is still unclear in some countries. This paper studies the components of the EWS as a reference for application in Indonesia.

Our contributions are summarized as follows:

1. We present a study on early warning system to obtain a general model of EWS structure.

2. We perform EWS latency and bit-error rate (BER) performances evaluation having 3, 4, and 5 nodes.

3. We perform BER performances of EWS per link system with rate $R=4 / 5$ and 64-QAM modulation based on [6].

The rest of the paper is organized as follows. The study and modeling of early warning system are presented in Section II. The EWS structure are presented in Section III. The system model of EWS per link is presented in Section IV. Sections V provides about the network latency. Section VI presents the system latency and BER performances of EWS and EWS per link. Finally, we conclude the paper in Section VII with some concluding remarks.

\section{Study on Emergency System}

Various warning systems have implemented on digital TV. USA adopted the ATSC as digital TV standard with an emergency system called Mobile Emer-

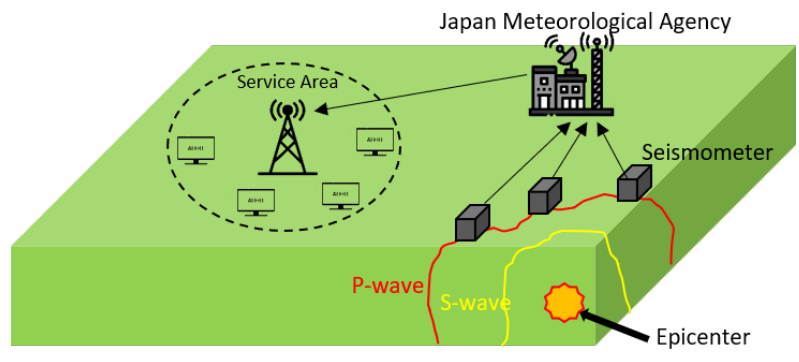

Fig. 2. Early earthquake warning information flow.

gency Alerting System (M-EAS). Fig. 1 shows the M-EAS signal transmission flow [7]. Emergency messages generated by the Federal Management Emergency Agency (FEMA) or local emergency manager. The emergency messages are processed into a standard format for digital TV by the M-EAS signal generation in a broadcast station. Then the M-EAS signals are broadcast to the digital TV receiver via TV broadcaster.

Japan uses the ISDB-T as digital TV standard. The emergency system defined as Emergency Warning Broadcasting System (EWBS). Fig. 2 shows the scheme of emergency information transmission on earthquake warning. The purpose of earthquake warning is to inform the public as soon as possible that an earthquake has occurred [8]. The emergency message received by Japan Meteorological Agency (JMA) through several sensors that detect earthquake $\mathrm{P}$-waves. The emergency information then forwarded to TV broadcaster to change into a transport stream and insert the triggering signal for activation. The triggering signal located in Transmission and Modulation Configuration Control (TMCC) [9]. The TV broadcaster then broadcast the emergency message to the TV receiver in the service area. The message then appear automatically at the receiver after receiving triggering signal.

In Korea, the emergency system defined as the Automatic Emergency Alert Service (AEAS). Korea adopted the Terrestrial Digital Multimedia Broadcasting (T-DMB) as digital TV standard. The DMB standard is based on Digital Audio Broadcasting (DAB) in Europe [10]. The emergency message format is designed concise and essential information for rapid delivery on a transport protocol of AEAS message [11]. Fig. 3 shows the transmission process of T-DMB emergency alert broadcasting. Korea Management Administration (KMA) or National Emergency Management Agency (NEMA) transmits an alert message to the T-DMB broadcasting station. The broadcasting station then converts the alert message into the AEAS signal format and segments the AEAS signal. The broadcasting station broadcasts the signals within the Fast Information Data Channel (FIDC) to public TV 


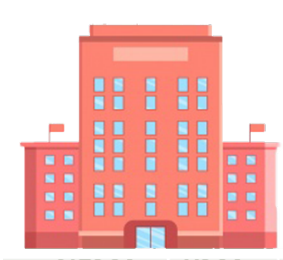

NEMA or KMA

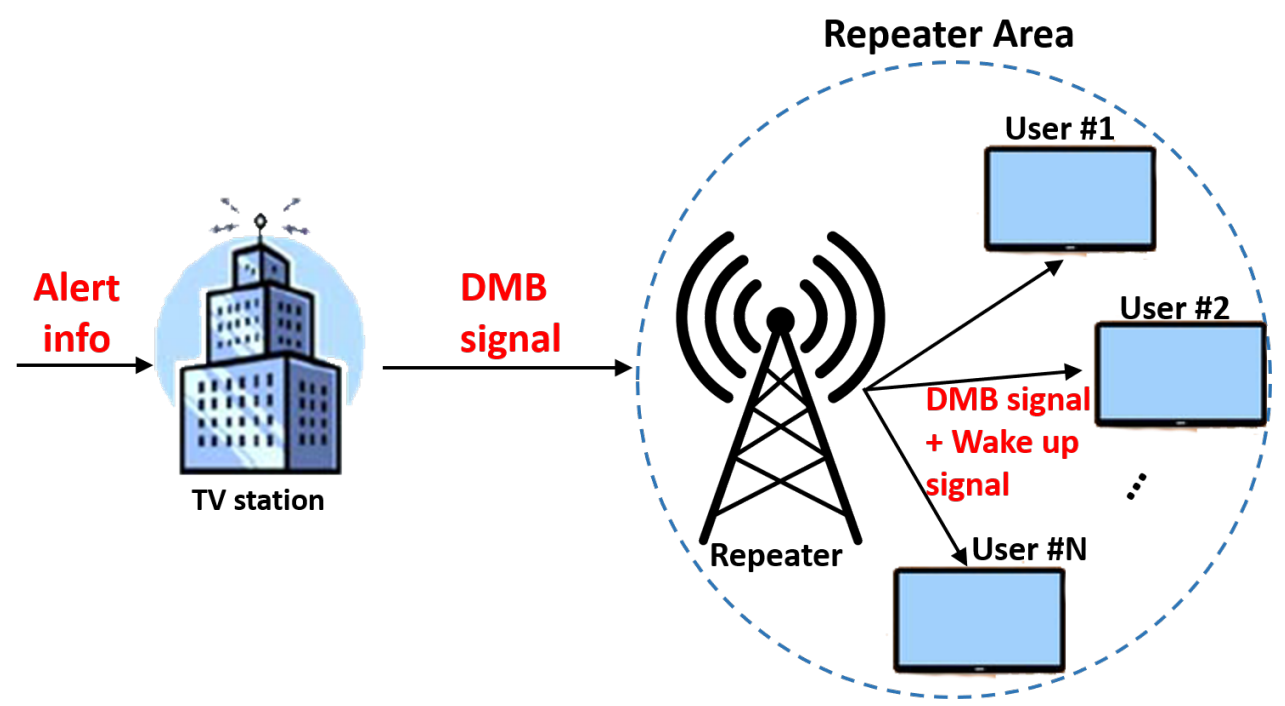

Fig. 3. AEAS emergency message transmission flow. receiver via repeater [3].

Indonesia uses Digital Video Broadcasting Terrestrial Second Generation (DVB-T2) as a digital television standard. DVB has an Announcement Service that allow the EWS message to interrupt the TV program as identified in "announcement support descriptor", of which the bit flags have length of 16 bits [12]. The trigger for real time announcement switching are encoded in the "private data byte" within the "adaptation field". The EWS message is located in the transport stream (TS) packet carrying the audio in service information (SI) format providing a certain item's content (metadata).

Since the SI bring the important information in bits, the SI should be protected and must have the lowest BER performances to avoid the error of "first priority" bits such that emergency alarm can be determined correctly by the receptor. This fact motivates us to evaluate the BER of EWS to protect for example, this SI bits. The syntax for determine the disaster specific informations have been arranged in [2]. The flow of emergency message transmission of DVB is proposed by [13]. The emergency agency received the emergency messages then forwarded to broadcasting station to generate the appropriate file for the digital TV packet stream. The packet stream is then transmitted and received by the receiver.

Based on the study, we modelled the minimum requirements of an emergency warning system into three nodes of emergency agency, broadcasting station, and TV receiver, respectively. The stages for the emergency system are detection of the emergency alert, generate the appropriate file for the digital TV packet stream, and receive the message by the receiver. On the detection stage, the emergency agency (meteorological agency or government) collects possible data about the disaster information. The collected data is sent to the broadcasting station to generates packet stream file based on the digital TV standards used. The packet is transmitted to the receiver and displayed in the TV service area.

\section{Early Warning System Structure}

This paper assumes the transmission of EWS information by passing through the emergency agency $\mathrm{s}$, broadcasting station $\mathrm{r}$, and TV receiver $\mathrm{d}$. The broadcasting station work as a relay to amplify the transmitted signal. Fig. 4 shows the scheme of EWS information transmission. The distance between emergency agency $\mathrm{s}$ and the destination $\mathrm{d}$ is $d_{s d}=2 d$. The distance of emergency agency to broadcasting station $d_{s r}=d$ and the TV transmitter to end terminal $d_{r d}=d$. Therefore the signal-to-noise power ratio (SNR) of each channels are [14]

$$
\begin{aligned}
& \gamma_{s r}=g_{s r} \gamma_{s d}, \\
& \gamma_{r d}=g_{r d} \gamma_{s d},
\end{aligned}
$$

where $g_{s r}$ and $g_{r d}$ are the gain of emergency agency to broadcasting station and broadcasting station to TV receiver given by $g_{s r}=\left(d_{s d} / d_{s r}\right)^{n}$ and $g_{r d}=$ $\left(d_{s d} / d_{r d}\right)^{n}$ respectively. $n$ denotes the path-loss exponent with $2 \leq n \leq 6$. In this paper we assume $n=3.52$ [14].

The received signals at each nodes can be written as

$$
\begin{aligned}
& y_{s r}=\sqrt{\gamma_{s r}} \cdot h_{s r} \cdot s+n_{s r}, \\
& y_{r d}=\sqrt{\gamma_{r d}} \cdot h_{r d} \cdot s_{r}+n_{r d},
\end{aligned}
$$

where $s$ and $s_{r}$ are the transmitted symbol vectors from emergency agency and broadcasting station re- 


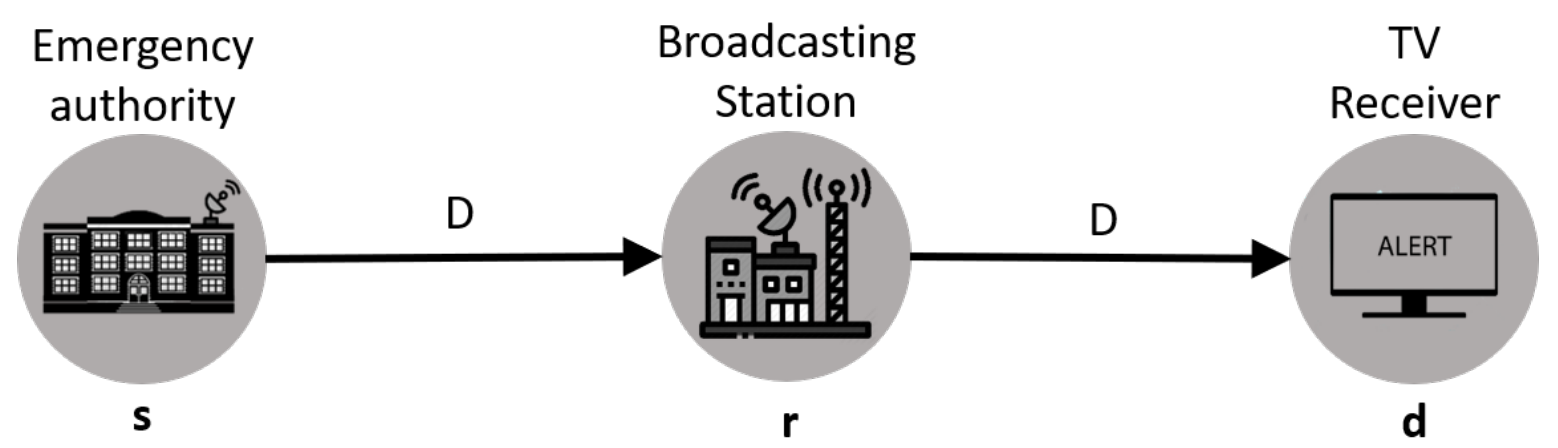

Fig. 4. EWS model with 3 nodes.

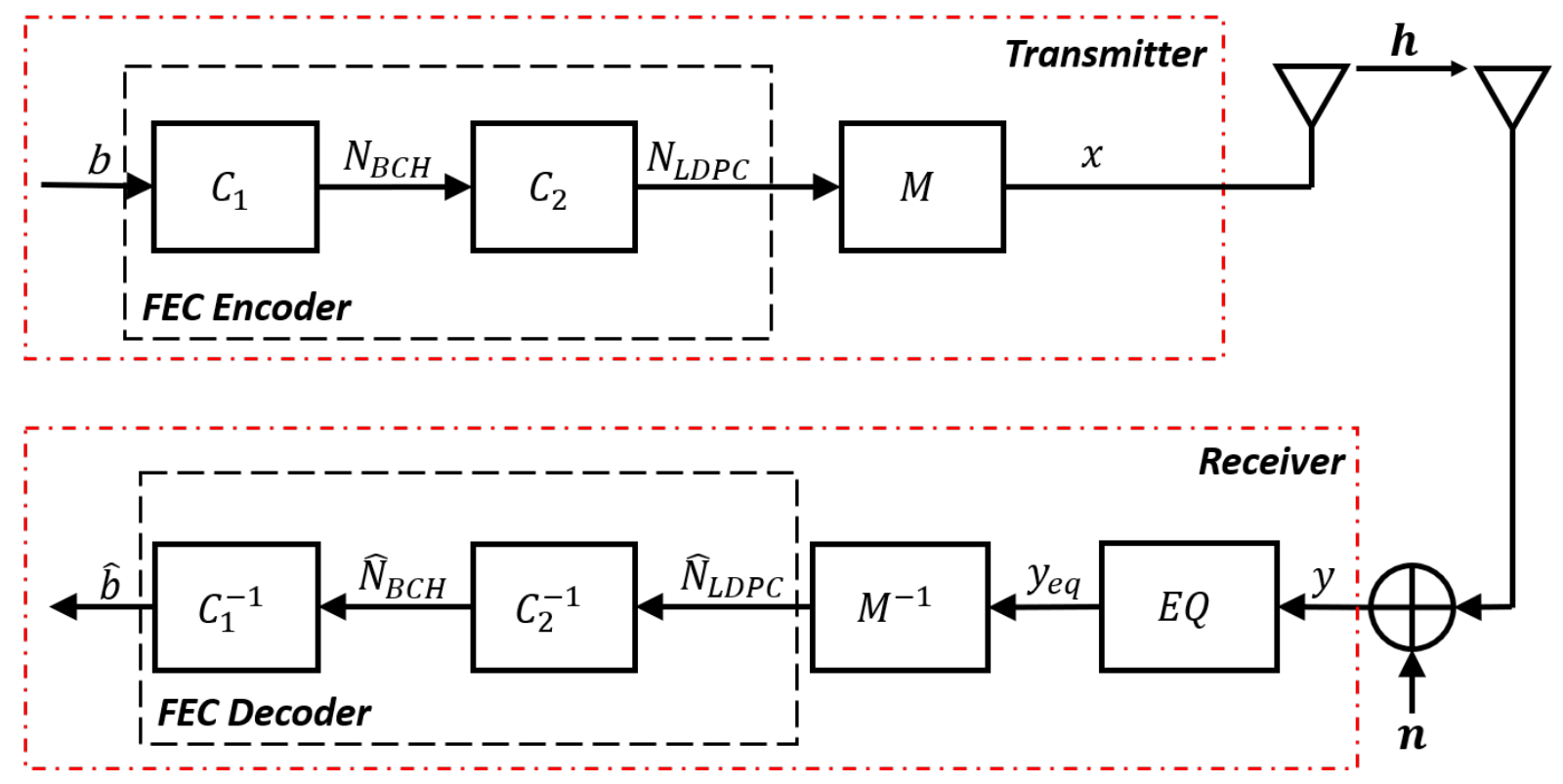

Fig. 5. The EWS per link transceiver system model.

spectively. $h_{s r}$ and $h_{r d}$ are frequency-flat fading channel gains for each channel. $n_{s r}$ and $n_{r d}$ are the noise vectors with variances for emergency agency to broadcasting station, broadcasting station to TV receiver respectively.

\section{System Model of EWS per Link}

Fig. 5 shows the transceiver structure of every link of EWS system. At the transmitter side, the bit stream b is generated randomly with equiprobable source. The bit stream is the input of forward error correction (FEC) encoder, of which the outer channel coding is Bose-Chaudhuri-Hocquenghem (BCH) codes encoder $C_{1}$, while the inner channel coding is Low Density Parity Check (LDPC) codes $C_{2}$ [15]. The evaluation of this link performance, with $\mathrm{BCH}$ and LDPC codes, is important, because we evaluate more than two hops to deliver the message of EWS system. With this evaluation, we can observe, whether many hops can be replaced by short hops or not. Furthermore, this evaluation is important to measure the loss due to the replacement of long hops with short hops.

We use the channel coding rate $R=4 / 5$ in accordance with ministerial regulations of Indonesia digital TV to generate codewords $\mathbf{N}_{\text {LDPC }}$. Codewords $\mathbf{N}_{\text {LDPC }}$ is then mapped using 64-QAM modulation in $M$ to generate symbol $\mathbf{x}$. The modulated symbol then transmitted over a fading channel with channel gain $h$. At the receiver side, a noise $\mathbf{n}$ is added and the received signal can be expressed as

$$
\mathbf{y}=h \cdot \mathbf{x}+\mathbf{n},
$$

with $h$ being the channel gain, $\mathbf{x}$ are the modulated symbols and $\mathbf{n}$ is an AWGN noise vector. Symbols $\mathbf{y}$ processed in equalization block EQ using Minimum Mean Squared Error (MMSE) equalizer [16]. Equalization of the received signal expressed as

$$
\mathbf{y}_{\mathbf{e q}}=\frac{\mathbf{y} \cdot h^{*}}{h \cdot h^{*}+\sigma^{2}},
$$


with $h^{*}$ is the complex-conjugate of the channel gain $h$ and $\sigma^{2}$ is variance of noise vector. The demodulation of 64-QAM symbol $\mathbf{y}$ is performed in $M^{-1}$ resulting $\hat{\mathbf{N}}_{\text {LDPC. Then the codewords are decoded using }}$ LDPC decoder $C_{2}^{-1}$ resulting $\hat{\mathbf{N}}_{\mathbf{B C H}}$ which is then decoded using $\mathrm{BCH}$ decoder $C_{1}^{-1}$. Then the decoded bit $\hat{b}$ is received. This paper compare the $\hat{\mathbf{b}}$ with the $\mathbf{b}$ to achieve the BER performances of EWS per link. Calculation BER in Rayleigh fading with 64-QAM modulation can be expressed as [17]

$$
P_{b, \text { Fading }}=\frac{7}{24}\left[1-\frac{1}{\sqrt{1+\frac{7}{E_{b} / N_{0}}}}\right]
$$

\section{Network Latency}

Latency is one of the measurements of network quality of service (QoS) [18]. Latency is classified into four parts of delay, i.e., processing time, queueing delay, transmission delay, and propagation delay for latency calculation. This paper use propagation delay and processing time. Processing time is the time for a device to process the data. This delay depends on the ability of the devices. We assume processing time $t_{\text {proc }}=2 \mu s$ for checking the data header and routing the data to the next node. Propagation delay is the time for a signal element (or bit) to propagate across the link. Propagation delay can be expressed as

$$
t_{\text {prop }}=\frac{d}{c},
$$

with $d$ being a distance from source to destination. This paper assumes a distance of $d_{s d}=6 \mathrm{~km}$ from source to destination. $c$ is the light velocity equals to $c=3 \times 10^{8} \mathrm{~m} / \mathrm{s}$.

\section{Performance Evaluations}

In this section, we analyze the performances of EWS delay and also verify the BER performances of EWS in AWGN and frequency-flat Rayleigh fading channel. This section also verify the BER performances of EWS per link.

\subsection{System Latency Analysis}

The delay performances are evaluated based on the number of nodes. Fig. 6 shows the achieved delay with different amount of nodes and distance between source to destination $d_{s d}=6 \mathrm{~km}$. The $\mathrm{x}$-axis is the number of nodes, while the y-axis is the delay. The achieved delay for EWS with 3 nodes equal to $26 \mu$ s and EWS with 4 nodes equal to $28 \mu$ s. The number of nodes affects the achieved delay because of the processing time for the packet in each node. The

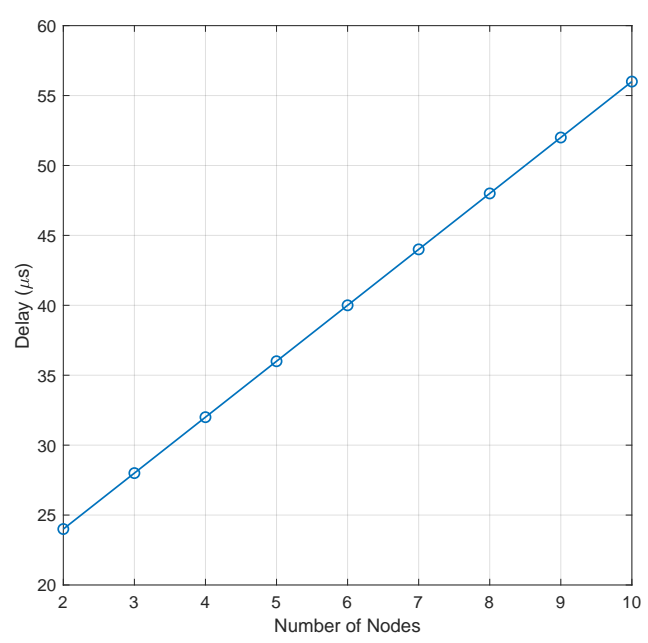

Fig. 6. Delay performances of EWS having several nodes and various distances per nodes for the same distance between source and destination of $d_{s d}=$ $6 \mathrm{~km}$.

achieved propagation delay based on (8) is

$$
\begin{aligned}
t_{\text {prop }} & =\frac{d_{s d}}{c} \\
& =\frac{6000 \mathrm{~m}}{3 \times 10^{8} \frac{\mathrm{m}}{\mathrm{s}}} \\
& =2 \times 10^{-5} \mathrm{~s} \\
& =20 \mu \mathrm{s} .
\end{aligned}
$$

The system latency can be minimized by reducing the distance between node. However, if the distance between source to destination has a significant value, the processing delay can be ignored. Based on the results, the latency of EWS with 3 nodes can be expressed as

$$
T=t+3 \Delta t
$$

Table 1: BER performances of EWS with 3 nodes separated by different distance between nodes.

\begin{tabular}{|c|c|c|c|c|}
\hline \multirow{2}{*}{$\begin{array}{c}\text { SNR } \\
(\mathrm{dB})\end{array}$} & \multicolumn{2}{|c|}{$\begin{array}{c}\text { Node Distance } \\
(\mathrm{km})\end{array}$} & $\begin{array}{c}\text { Total Delay } \\
(\mu \mathrm{s})\end{array}$ & \multirow{2}{*}{ BER } \\
\cline { 2 - 5 } & $1-2$ & $2-3$ & & \\
\hline \multirow{5}{*}{20} & 0.5 & 5.5 & 28 & $42 \times 10^{-3}$ \\
\cline { 2 - 5 } & 0.75 & 5.25 & 28 & $35 \times 10^{-3}$ \\
\cline { 2 - 5 } & 1 & 5 & 28 & $32 \times 10^{-3}$ \\
\cline { 2 - 5 } & 1.25 & 4.75 & 28 & $27 \times 10^{-3}$ \\
\cline { 2 - 5 } & 1.5 & 4.5 & 28 & $23 \times 10^{-3}$ \\
\cline { 2 - 5 } & 1.75 & 4.25 & 28 & $20 \times 10^{-3}$ \\
\cline { 2 - 5 } & 2 & 4 & 28 & $17 \times 10^{-3}$ \\
\cline { 2 - 5 } & 2.25 & 3.75 & 28 & $14 \times 10^{-3}$ \\
\cline { 2 - 5 } & 2.5 & 3.5 & 28 & $13 \times 10^{-3}$ \\
\cline { 2 - 5 } & 2.75 & 3.25 & 28 & $12 \times 10^{-3}$ \\
\cline { 2 - 5 } & 3 & 3 & 28 & $10 \times 10^{-3}$ \\
\hline
\end{tabular}


Table 2: BER performances of EWS system with 4 nodes separated by different distance of between nodes.

\begin{tabular}{|c|c|c|c|c|c|}
\hline \multirow{2}{*}{$\begin{array}{c}\text { SNR } \\
(\mathrm{dB})\end{array}$} & \multicolumn{3}{|c|}{$\begin{array}{c}\text { Node Distance } \\
(\mathrm{km})\end{array}$} & $\begin{array}{c}\text { Total Delay } \\
(\mu \mathrm{s})\end{array}$ & BER \\
\cline { 2 - 4 } & $1-2$ & $2-3$ & $3-4$ & & \\
\hline \multirow{5}{*}{20} & 0.5 & 2 & 3.5 & 32 & $100 \times 10^{-4}$ \\
\cline { 2 - 6 } & 1 & 1 & 4 & 32 & $160 \times 10^{-4}$ \\
\cline { 2 - 6 } & 1 & 2 & 3 & 32 & $73 \times 10^{-4}$ \\
\cline { 2 - 6 } & 1.5 & 1.5 & 3 & 32 & $70 \times 10^{-4}$ \\
\cline { 2 - 6 } & 2 & 1 & 3 & 32 & $78 \times 10^{-4}$ \\
\cline { 2 - 6 } & 2 & 2 & 2 & 32 & $41 \times 10^{-4}$ \\
\hline
\end{tabular}

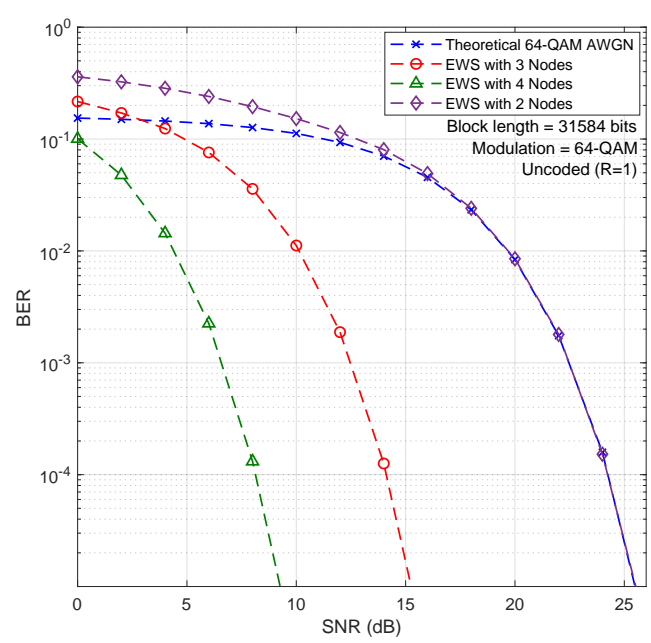

Fig. 7. EWS BER performances in AWGN channel.

with $t$ being the propagation delay in (8) and $\Delta t$ is the processing time.

\subsection{EWS BER Performances}

BER of the system can be calculated as

$$
B E R=\frac{e}{n \times f},
$$

where $e$ is the total of error bit during transmission, $n$ is the information block length, and $f$ is the total of the frame. We evaluate the BER performances of the EWS in terms of SNR $\gamma$, which is expected to be used as EWS implementations in Indonesia.

Table 1 and Table 2 show the BER performances at SNR $\gamma=20 \mathrm{~dB}$ with different distance for each nodes. The tables data show that the smallest BER performances achieved at an equal distance for each node. The lowest BER performance in table 1 for EWS with 3 nodes is equal to $1 \times 10^{-2}$ and in table 2 for EWS with 4 nodes is approximate to $4 \times 10^{-3}$. Based on the results, to verify the BER performances, we used equal distance for each node.

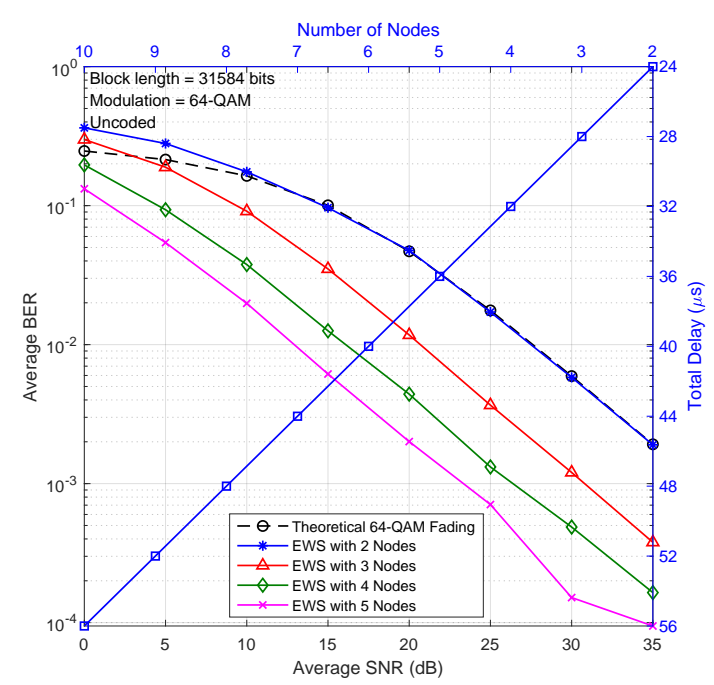

Fig. 8. BER and delay performances of EWS system under frequency-flat Rayleigh fading.

Fig. 7 shows the EWS BER performances in the AWGN channel. The $\mathrm{x}$-axis is the SNR, while the $\mathrm{y}$-axis is the BER. The BER performances of $P_{b}=$ $10^{-4}$ is achieved by the EWS with 3 and 4 nodes at $\gamma=14.2 \mathrm{~dB}$ and $\gamma=8.2 \mathrm{~dB}$, respectively. The curve gap between the EWS with 2 nodes and the EWS with 3 and 4 nodes reach $10 \mathrm{~dB}$ and $16 \mathrm{~dB}$, respectively.

Fig. 8 shows the EWS BER performances in the frequency-flat Rayleigh fading channel. The lower $\mathrm{x}$-axis is the average SNR, while the left $\mathrm{y}$-axis is the average BER, and the upper $\mathrm{x}$-axis is the number of nodes, while the right $y$-axis is the total delay. The BER performances of $P_{b}=10^{-3}$ is achieved by the EWS with 3, 4, and 5 nodes at $\gamma=31.6 \mathrm{~dB}$, $\gamma=26.3 \mathrm{~dB}$, and $\gamma=23.6 \mathrm{~dB}$, respectively. The curve gap of the EWS with 2 nodes and EWS with 3, 4 , and 5 nodes reach $6.2 \mathrm{~dB}, 11.5 \mathrm{~dB}$, and $14.2 \mathrm{~dB}$, respectively. The EWS with 5 nodes has better performance than the EWS with 3 and 4 nodes, because the additional nodes make the distance between nodes shorter such that the signal is received with higher quality. Furthermore, every node performs decoding and re-encoding that makes the error correction capability larger.

However, the node addition does not improve the performances significantly, but increase the system delay and computational complexity, which is in general, the block length cannot be made below $N=10^{4}$ [19]. Implementation of decoding therefore require this block length, which is also requiring storage and memory management. Therefore, we assume that EWS with 3 or 4 nodes are enough with acceptable computational complexity. 


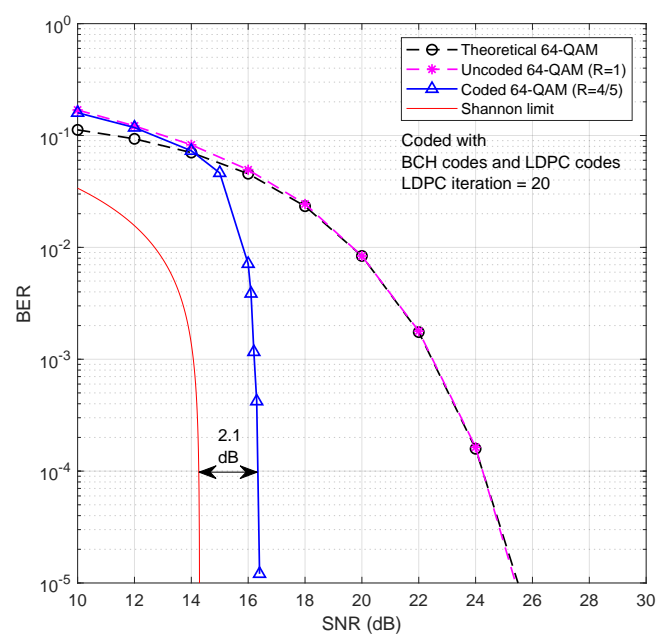

Fig. 9. BER performances of EWS per link in AWGN channels.

\subsection{EWS per Link BER Performances}

This section evaluates the BER performances of EWS per link in AWGN and frequency-flat Rayleigh fading channel with 64-QAM modulation. Fig. 9 shows the BER performances of EWS per link system in the AWGN channel. The $\mathrm{x}$-axis is the SNR, while the $y$-axis is the BER. The BER performances with rate $R=4 / 5$ has $P_{b}=10^{-4}$ at $\gamma=16.4 \mathrm{~dB}$. The curve gap between EWS with $R=4 / 5$ with Shannon limit of $P_{b}=10^{-4}$ is about $\gamma=2.1 \mathrm{~dB}$. The EWS BER performances have an improvement of $17.9 \mathrm{~dB}$ compared to the same system without channel coding. The BER performances show that the EWS parameter via digital TV is good enough because the performances approach Shannon limit that means the power loss is getting smaller.

Fig. 10 shows the BER performances of EWS per link system in the frequency-flat Rayleigh fading channel. The $\mathrm{x}$-axis is the average SNR, while the $\mathrm{y}$-axis is the average BER. The BER performances with $R=4 / 5$ has $P_{b}=10^{-3}$ at $\gamma=35.3 \mathrm{~dB}$. The curve did not have diversity order two or more because the Rayleigh fading channel did not has a diversity effect. The BER performances of EWS per link in Rayleigh fading channel have the same gradient as the theoretical fading because one block experiencing the same fading and does not has a diversity effect. The channel coding used is not very helpful because one block has the same fading.

\section{Conclusion}

This paper has studied the EWS for Indonesia and modeled EWS into 3 nodes consisting of (i) emergency agency, (ii) broadcasting station, and (iii) TV receiver. The EWS performances are evaluated using

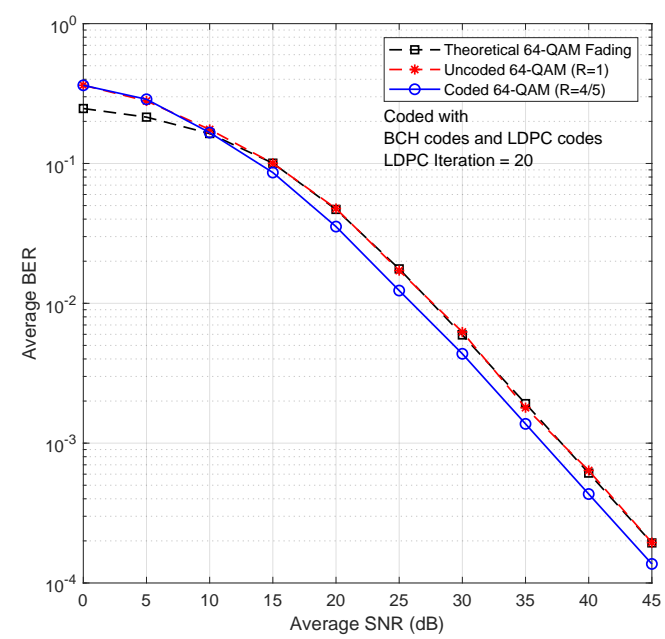

Fig. 10. BER performances per link of EWS per link in frequency-flat Rayleigh fading channel.

latency and BER performances with 64-QAM modulation. We confirmed that the EWS with 5 nodes or more has a better BER performance compared to the EWS with 3 and 4 nodes, but having latency $T \geq t+5 \Delta t$ causes larger delay. The addition of nodes can improve the BER performances, but the use of more nodes causes larger latency of the system and higher computational complexity requiring storage and memory management. We proposed an EWS with only 3 or 4 nodes and found that 3 or 4 nodes are enough to achieve good performances with (i) latency criterion $T \leq t+4 \Delta t$ and (ii) BER performances less than $P_{b}=10^{-3}$. The result of this paper is expected to be a reference for implementing the EWS in Indonesia.

\section{References}

[1] ITU-R, "Transition from analogue to digital terrestrial broadcasting," Tech. Rep., May 2011.

[2] Menkominfo, "Peraturan Menteri Komunikasi dan Informatika Republik Indonesia Nomor 3 Tahun 2014 tentang Persyaratan Teknis Sistem Peringatan Dini Bencana Alam pada Alat dan Perangkat Penerima Televisi Siaran Digital Berbasis Standar Digital Video Broadcasting Terrestrial," January 2014.

[3] I. Jeon, M. Song, S. Chang, S. J. Choi, and Y. Lee, "A signaling emergency alert system multiplexed with T-DMB channel for emergency alert service," IEEE Transactions on Consumer Electronics, vol. 61, no. 1, pp. 16-23, February 2015.

[4] S. Takahashi, "A novel method of determining EWS wake-up trigger for ISDB-T digital television receivers," in 2014 IEEE 10th International 
Conference on Wireless and Mobile Computing, Networking and Communications (WiMob), Oct 2014, pp. 348-353.

[5] Y. Wahyu, M. S. H. Shiddiq, and M. Wahab, "Design and realization of an early warning system for natural disaster on digital television in Indonesia," in IEEE international Symposium on Broadband Multimedia Systems and Broadcasting, June 2012, pp. 1-4.

[6] Menkominfo, "Peraturan Menteri Komunikasi dan Informatika Republik Indonesia nomor 6 tahun 2019 tentang rencana induk frekuesi radio untuk keperluan penyelenggaraan televisi siaran digital terestrial pada pita frekuensi radio ultra high frequency," July 2019.

[7] Advanced Television Systems Committee, ATSC Mobile Emergency Alert System A Guide to Implementation, March 2013.

[8] T. Ohsumi, "Development of real-time damage estimation system for embankment using earthquake early warning," in 2013 International Conference on Signal-Image Technology InternetBased Systems, Dec 2013, pp. 854-859.

[9] ARIB, "Transmission system for digital terrestrial television broadcasting," Tokyo: Association of Radio Industries and Business (ARIB), Standard, November 2005.

[10] ETSI, "Radio broadcasting systems; digital audio broadcasting (DAB) to mobile, portable and fixed receivers," European Telecommunications Standards Institute (ETSI), Standard, June 2006.

[11] S. Kwon, H. Jun, S. Lee, and K. Kwon, "TII based T-DMB location AEAS receiver model," in 2009 IEEE International Conference on Multimedia and Expo, June 2009, pp. 1286-1289.

[12] ETSI, "Digital Video Broadcasting (DVB); specification for Service Information (SI) in DVB systems," European Telecommunications Standards Institute (ETSI), Standard, March 2016.

[13] R. Azmi, H. Budiarto, and R. Widyanto, “A proposed disaster emergency warning system standard through DVB-T in Indonesia," in Proceedings of the 2011 International Conference on Electrical Engineering and Informatics, July 2011, pp. 1-4.

[14] K. Anwar and T. Matsumoto, "Accumulatorassisted distributed turbo codes for relay systems exploiting source-relay correlation," IEEE Communications Letters, vol. 16, no. 7, pp. 11141117, July 2012.
[15] ETSI, "Digital Video Broadcasting (DVB); frame structure channel coding and modulation for a second generation terestrial television broadcastig system (DVB-T2)," Standard, June 2015.

[16] J. G. Proakis, Digital Communications. McGraw-Hill, 1995.

[17] H. Harada and R. Prasad, Simulation and Software Radio for Mobile Communications. USA: Artech House, Inc., 2002.

[18] A. Hernandez and E. Magana, "One-way delay measurement and characterization," in International Conference on Networking and Services (ICNS '07), June 2007, pp. 114-114.

[19] C. Schlegel and L. Perez, Trellis and Turbo Coding. Hoboken, NJ, USA: John Wiley \& Sons, Inc., 2003.

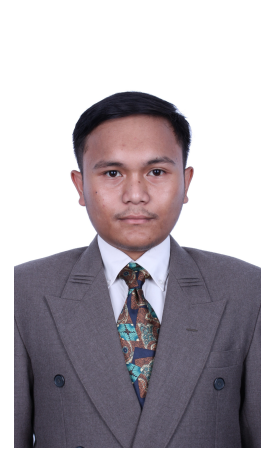

Sulthon Faryabi Nurbadri was born in Tanjungpandan, November $13^{\text {th }}$ 1998. Sulthon is pursuing a Bachelor's Degree in Telecommunication Engineering at the School of Electrical Engineering, Telkom University. Sulthon is a researcher in Advanced Intelligent Communications (AICOMS). Sulthon takes a research topic about early warning systems for digital television. His research interest include channel coding, modulation, digital television, and warning system.

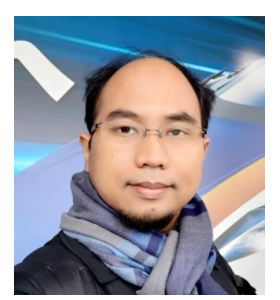

Khoirul Anwar (SM16) received the bachelors degree (cum laude) from the Department of Electrical Engineering (Telecommunications), Bandung Institute of Technology (ITB), Bandung, Indonesia, in 2000, and the masters and Ph.D. degrees from the Graduate School of Information Science, Nara Institute of Science and Technology, Nara, Japan, in 2005 and 2008, respectively. He was with the University of Melbourne, Australia, in 2007, the University of Oulu, Finland, in 2010, and Cranfield University, U.K., in 2018, as a Visiting Researcher. In 2008, he was with the School of Information Science, Japan Advanced 
Institute of Science and Technology, as an Assistant Professor. Since 2016, he has been with the School of Electrical Engineering, Telkom University, Bandung, as an Associate Professor, and the Director of the Center for Advanced Wireless Technologies (AdWiTech). Since July 2020 the AdwiTech transformed as the National University Center of Excellent for Advanced Intelligent Communications (AICOM). He has been the Chairman of WG Radio and Technologies of Indonesia 5G Forum and the Chairman of the Asia Pasific Telecommunity Wireless Group on Service and Applications, 2016-2019. Dr. Anwar is currently the Vice-chairman of the Asia Pasific Telecommunity Wireless Group, 20192021.

His research interests are network information theory, error correction coding, iterative decoding, coding for super-dense networks, and signal processing for wireless communications. His technique is adopted by the international telecommunication union (ITU), ITUR standard No. ITU-R S.2173Multi- Carrier-Based Transmission Techniques, and ITU-R S.1878Multicarrier Based Transmission Techniques for Satellite Systems. He is a Senior Member of the IEEE Information Theory Society and Communications Society.

He received the Best Student Paper Award at the IEEE Radio and Wireless Symposium 2006 (RWS06), CA, USA, the Best Paper Award of Indonesian Student Association (ISA 2007), Kyoto, Japan, in 2007, the Best Paper Presenter for the Advanced Technology at the International Conference on Sustainability for Human Security (SUSTAIN), Kyoto, in 2011, the Indonesian Diaspora Award for Innovation, Congress of Indonesian Diaspora, Los Angeles, USA, in 2012, the Achmad Bakrie Award 2014, Jakarta, in 2014, and the Anugerah of Internationally Recognized Contributions from the Governor of West Java, Indonesia, in 2016, the National Achievement Award from UKP-PIP Pancasila, Jakarta, in 2017, OCBC award of Innovation in August 2019. He serves as a reviewer for a number of main journals and conferences in the areas of wireless communications, coding theory, and signal processing.

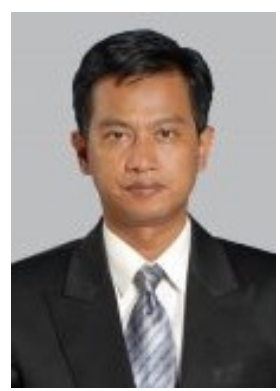

Dharu Arseno received bachelor degree and master's degree from the Departement of Electrical Engineering, Bandung Institute of Technology (ITB) in 1995 and 2001, respectively. Dharu is currently a senior lecturer at School of Electrical Engineering, Telkom University since 2002. His research interest and radar. is on wireless communications 